\title{
Posterior Surface of the Vagina
}

National Cancer Institute

\section{Source}

National Cancer Institute. Posterior Surface of the Vagina. NCI Thesaurus. Code C33383.

The posterior aspect of the vagina. 